\title{
Thyroid 'hot' nodules
}

\author{
IAN RAMSAY* \\ M.D., M.R.C.P., M.R.C.P.E. \\ Philip Marsden \\ B.Sc., M.B., M.R.C.P. \\ P. J. RICHARDSON \\ C. G. MCKERRON \\ M.B., M.R.C.P. \\ M.B., M.R.C.P.

\begin{abstract}
Department of Medicine, King's College Hospital Medical School, Denmark Hill, London, S.E.5
\end{abstract}

\begin{abstract}
Summary
A retrospective analysis of thyroid scintiscanning at one hospital over a 3-year period revealed nineteen patients in whom a solitary, hyperfunctioning thyroid nodule was producing thyrotoxicosis.

Most of the patients had clinical features referable to hyperthyroidism and in the majority a solitary nodule was palpable in the neck which was found to correlate well with the location of the 'hot' nodule on scanning. Cardiac failure was present in $21 \%$ and atrial fibrillation occurred in $37 \%$.

The ${ }^{131} \mathrm{I}$ uptake by the thyroid was of little value in deciding whether or not the patient was toxic, but there was good agreement between serum protein bound iodine determinations and measurement of serum thyroxine and resin uptake tests. There appeared to be no relationship between the size of the nodule and its degree of activity.
\end{abstract}

\section{Introduction}

An autonomous, hyperfunctioning thyroid nodule ('hot' nodule) has been well established as a cause of thyrotoxicosis (Cope, Rawson \& McArthur, 1947; Sheline \& McCormack, 1960). This situation was, however, considered to be rare (Roualle, 1949), only four patients having been seen in an academic surgical unit at St Batholomew's Hospital, London, between 1938 and 1947 and ten patients in 10 years at the Mayo Clinic, reported at about the same time (Cope et al., 1947). Recently, with the increased use of radio-isotope scanning, toxic nodules are being more frequently recognized (Demeester-Mirkine \& Ermans, 1967), though Silverstein and his colleagues maintain that they are rare (Silverstein, Burke \& Cogan, 1967).

Experience with thyroid scanning at King's College Hospital suggested that the presence of a solitary hyperfunctioning nodule was not an un-

\footnotetext{
* Correspondence: Dr Ian Ramsay, Regional Endocrine Centre, North Middlesex Hospital, London, N.18.
}

common occurrence and that there appeared to be little difference between the size of nodules in those patients with, and those without, thyrotoxicosis. It was therefore decided to make a retrospective examination of the data collected over a 3-year period between August 1968 and August 1971.

\section{Methods}

An ${ }^{131}$ I uptake was performed by the Radiotherapy Department using a standard technique. An oral dose of $50 \mu \mathrm{Ci}$ was routinely given with the sanction of the MRC Radio-active Isotopes Advisory Panel to all patients with thyroid disease on whom a scan was requested by the referring clinician. Some patients investigated at the request of the Endocrine Clinic received $20 \mu \mathrm{Ci}$. The uptake was measured by a sodium iodide (Tl) crystal 1 in. in diameter and 1 in. thick positioned $30 \mathrm{~cm}$ from the patient's neck. The energy range used was from 110 to $420 \mathrm{KeV}$. A standard solution in $25 \mathrm{ml}$ of water placed in a phantom neck made of perspex was counted at $30 \mathrm{~cm}$ from the crystal before each measurement on the patient. The response of the detector to a point source was uniform over a circle of radius $5.5 \mathrm{~cm}$ at $30 \mathrm{~cm}$ from the crystal. At a point $3 \mathrm{~cm}$ outside the periphery of the circle the uptake measured on the phantom fell to $5 \%$. Room background counts were subtracted from the thyroid counts. Since measurements over the neck well away from the thyroid showed less than $2 \%$ activity at $24 \mathrm{hr}$, any error from ${ }^{131} \mathrm{I}$ in extrathyroidal tissue was ignored while measuring uptake over the thyroid gland. The higher background counts to be expected at the time of the 2- and 6-hr uptakes would of course give higher rather than lower thyroidal uptakes. The uptake was measured at 2, 6, 24 and $48 \mathrm{hr}$ (upper limits of normal $22,34,53$ and $53 \%$ respectively). The PB ${ }^{131} \mathrm{I} \%$ of dose/ 1 of plasma was estimated at $48 \mathrm{hr}$ (upper limit of normal $0 \cdot 4 \%$ ). At $24 \mathrm{hr}$ a thyroid scan was performed using a Picker Magna 
Scanner V with a 5 in. fine focus collimator (Collimator 2111A). The resolution at $5 \mathrm{in}$. in air was 1.0 $\mathrm{cm}$ (full width half maximum) for a point source with ${ }^{131}$ I. The scan speed was $30 \mathrm{~cm} / \mathrm{min}$ with line spacing at $0.35 \mathrm{~cm}$, so that neighbouring lines were continuous. The printer was set for red at the peak count rate; other colours were printed for lower count rates, the colour changes occurring every $12.5 \%$ of the maximum count rate. The background count rate at $24 \mathrm{hr}(<2 \%)$ was negligible.

Scans were classified as showing a single hyperfunctioning thyroid nodule if they met with the following criteria: (1) Uptake was confined to one discrete area, with no uptake in the rest of the gland. (2) There was no clinical or pathological evidence of carcinoma of the opposite lobe or of a multinodular goitre. (3) There had been no previous thyroid surgery. (4) There was no clinical or investigative indication of thyroiditis. (5) There had been no administration of antithyroid drugs in the previous 6 weeks.

The nodules were classified arbitrarily into 'toxic' if the PBI was above $7.8 \mu \mathrm{g} / 100 \mathrm{ml}$, or 'non-toxic' if the PBI was below $7.8 \mu \mathrm{g} / 100 \mathrm{ml}$.

The surface area of the solitary hyperfunctioning nodules was analysed by an independent observer without knowledge of other investigations. The surface area of the nodule, which was invariably oval, was calculated using the formula $\frac{\pi}{4} \cdot d . D$, where $d=$ width and $D=$ length.

The serum protein bound iodine (PBI) estimations were performed by a fully automatic method (Riley \& Gochman, 1964) modified by the use of commercially assayed sera in place of the inorganic standards. The normal range for the laboratory is $3 \cdot 3-7 \cdot 8 \mu \mathrm{g} / 100 \mathrm{ml}$.

Total thyroxine iodine $\left(\mathrm{T}_{4} \mathrm{I}\right)$ was performed using a modification of Murphy \& Pattee's (1964) relative binding technique. The normal range is $3 \cdot 2-7 \cdot 2 \mu \mathrm{g} /$ $100 \mathrm{ml}$.

Triiodothyronine resin uptake $\left(T_{3} R U\right)$ was measured with Thyopac 3 (Radiochemical Centre, Amersham), the normal range being expressed as $93-121 \%$ of normal; a value less than $93 \%$ indicates thyrotoxicosis.

Total thyroxine $\left(\mathrm{T}_{4}\right)$ was measured (Maclagen \& Howorth, 1969), the normal value being 4.0-11.0 $\mu \mathrm{g} / 100 \mathrm{ml}$. Thyroxine resin uptake ratio $\left(\mathrm{T}_{4} \mathrm{RUR}\right)$ was performed (Maclagan \& Howorth, 1969), the normal ratio being $0 \cdot 92-1 \cdot 20$. Values above $1 \cdot 20$ indicate thyrotoxicosis. From the $T_{4} R U R$ and the $\mathrm{T}_{4}$ the free thyroxine index $\left(\mathrm{FT}_{4} \mathrm{I}\right)$ was calculated (Maclagan \& Howorth, 1969), the normal range being $4 \cdot 5-11 \cdot 5$.

The initial clinical case records of each patient were examined for symptoms (nervousness, weight loss, palpitations, breathlessness, tiredness, heat intolerance and ankle swelling) and signs (lid lag, tachycardia, arrhythmias, sweating and evidence of heart failure) which suggested a diagonosis of thyrotoxicosis. The presence or absence of exophthalmos was also noted. The response to treatment was considered 'good' if the original symptoms disappeared, weight was gained and the pulse rate became normal. The response was 'partial' if the above criteria improved, but were still present. PBI's or other in vitro tests $\left(T_{4}, T_{4} R U R\right.$ and $\left.F_{4} I\right)$ were available in all but one of the patients who had been treated and post-treatment ${ }^{131} \mathrm{I}$ scans had been done on six patients.

\section{Results}

\section{Incidence}

In a 3-year period up to August 1971, thirty-four solitary 'hot' nodules were seen, of which nineteen were toxic, nine were non-toxic and six could not be classified because the PBI had not been done. Since more scans are done now than in 1968, an analysis of the solitary 'hot' nodules over the year August 1970-August 1971 revealed that fifteen were diagnosed, of which seven were toxic, five were nontoxic and in three a PBI value was not available.

\section{Position of nodule}

The position of the nodule within the thyroid gland was not different in any of the three groups. It was? in the right lobe in seventeen cases, the left lobe in fifteen and in the isthmus in two cases.

\section{Sex of patients}

Overall, there was a nearly $6: 1$ female : male sex ratio for solitary 'hot' nodules, though the ratio was just less than $3: 1$ when only toxic 'hot' nodules were considered.

\section{Age at diagnosis}

The mean age at diagnosis of the toxic patients was $58 \pm 14 \cdot 2$ (SD) years, range 19-82 years, and that of the non-toxic patients $52.0 \pm 14.7$ years, range $25-72$ years. The age difference between the two groups was not significant.

\section{Clinical presentation}

Fourteen of the nineteen patients with a PBI of more than $7 \cdot 8 \mu \mathrm{g} / 100 \mathrm{ml}$ had both symptoms and signs suggestive of thyrotoxicosis. Four patients had symptoms but no signs and one patient had neither symptoms nor signs of hyperthyroidism. Four of the nineteen patients had evidence of heart failure $(21 \%)$ and all four had atrial fibrillation. A further three patients without heart failure had atrial fibrillation, making a total incidence of atrial fibrillation of $37 \%$. Table 1 shows a comparison of the presenting 
TABLE 1. Presenting symptoms in patients with toxic and non-toxic 'hot' nodules

\begin{tabular}{lcc}
\hline & $\begin{array}{c}\text { Toxic } \\
n=19\end{array}$ & $\begin{array}{c}\text { Non-toxic } \\
n=9\end{array}$ \\
\hline Anxiety & 10 & 3 \\
Weight loss & 8 & 1 \\
Palpitations & 6 & 1 \\
Breathlessness & 6 & 1 \\
Depression & 4 & 3 \\
Tiredness & 4 & 0 \\
Heat intolerance & 4 & 0 \\
Lump in neck & 4 & 5 \\
Ankle swelling & 3 & 0 \\
Muscle weakness & 1 & 0 \\
Choking and/or dysphagia & 1 & 1 \\
\hline
\end{tabular}

symptoms in the patients with toxic 'hot' nodules compared with those whose PBI was less than 7.8 $\mu \mathrm{g} / 100 \mathrm{ml}$ (non-toxic). It can be seen that symptoms suggestive of thyrotoxicosis were not conspicuous in the latter group, apart from anxiety, and they tended to present more often with a lump in the neck. None of the patients had exophthalmos or any changes of infiltrative ophthalmopathy.

In fifteen toxic patients examination of the neck revealed a single palpable nodule in the thyroid which correlated in every case with the 'hot' area on scanning. In three cases the thyroid was not palpable clinically and in the remaining case was retrosternal.

\section{Radio-active iodine uptakes}

As can be seen from the data in Table 2, of the eighteen toxic patients, with PBIs above $7.8 \mu \mathrm{g} / 100$ $\mathrm{ml}$, on whom full data are available, only nine $(50 \%)$ had a raised uptake of ${ }^{131}$ I at either $2,6,24$ or $48 \mathrm{hr}$. In only four patients was it raised at all four times of measurement. In three patients it was elevated in one reading solely, and that was at $6 \mathrm{hr}$ in each case. In one-third of the patients the ${ }^{131} \mathrm{I}$ uptake and $48 \mathrm{hr} \mathbf{P B}^{131}$ I were completely normal. In a sixth of the patients the raised 48-hr PB $^{131}$ I was the only abnormal finding.

Of the patients who were classified as non-toxic on the basis of the PBI, five out of the eight had normal results. However, of the remaining three patients, one had a raised uptake and $\mathbf{P B}^{131} \mathrm{I}$, one had an increased uptake alone and the third had a high $\mathrm{PB}^{131} \mathrm{I}$ as the only abnormality.

There was no statistical significance between the two groups for any of the parameters measured by the use of ${ }^{131}$ I (Table 3).

Contribution to the diagnosis made by $T 4, T 4$ resin uptake and $T 3$ resin uptake (Table 3 )

In four patients, 'toxic' on PBI criteria, in whom measurements of $T_{4} I$ were made, all had elevated values. In two of them the $T_{3} R U$ was also in the thyrotoxic range. A further toxic patient, in whom $\mathrm{T}_{4}, \mathrm{~T}_{4} \mathrm{RUR}$ and $\mathrm{FT}_{4} \mathrm{I}$ were measured, had results which confirmed the diagnosis.

There was, however, a poor correlation between the above results and those of ${ }^{131}$ I uptake, for in two of the five patients the uptake was normal. There was better agreement with $\mathbf{P B}^{131} \mathrm{I}$, in that four out of the five patients had an elevated $\mathbf{P B}^{131} \mathrm{I}$.

In the three non-toxic patients in whom measurements were made, all were in the normal range, even though one patient had an elevated ${ }^{131}$ I uptake. Measurements of circulating thyroxine and resin uptake appear to correlate well with PBI, less well with PB $^{131}$ I but poorly with the ${ }^{131}$ I uptake.

\section{Area of the nodule}

The area of the nodules, calculated from the scan was $6 \cdot 24 \pm 2.76 \mathrm{~cm}^{2}$ for the toxic patients and $5 \cdot 20$

TABLE 3. The mean 6- and 24-hr ${ }^{131}$ Iuptakes and 48-hr PB $^{131}$ I values in toxic and non-toxic patients with 'hot' nodules

\begin{tabular}{|c|c|c|c|}
\hline & \multicolumn{2}{|c|}{$\% \quad{ }^{131}$ I uptake } & \multirow{2}{*}{$\begin{array}{c}\text { 48-hr } \\
\mathrm{PB}^{131} \mathrm{I} \pm \mathrm{SD}\end{array}$} \\
\hline & $6 \mathrm{hr} \pm \mathrm{SD}$ & $24 \mathrm{hr} \pm \mathrm{SD}$ & \\
\hline $\begin{array}{l}\text { Toxic } \\
\qquad n=19\end{array}$ & $32 \pm 13$ & $45 \pm 14$ & $0.63 \pm 047$ \\
\hline $\begin{array}{l}\text { Non-toxic } \\
n=9\end{array}$ & $27 \pm 12$ & $42 \pm 14$ & $0.36 \pm 023$ \\
\hline $\begin{array}{l}\text { Statistical } \\
\text { significance } \\
\text { between the } \\
\text { two groups }\end{array}$ & $\begin{array}{c}\text { Not } \\
\text { significant }\end{array}$ & $\begin{array}{c}\text { Not } \\
\text { significant }\end{array}$ & $\begin{array}{c}\text { Not } \\
\text { significant }\end{array}$ \\
\hline
\end{tabular}

TABLE 2. The uptake of ${ }^{131} I$ and the $48-h r P^{131} I$ in patients with solitary 'hot' nodules

\begin{tabular}{lcccc}
\hline Classification & \multicolumn{1}{c}{ 131 I uptake and 48-hr PB ${ }^{131}$ I } & \begin{tabular}{c} 
131 I uptake \\
alone \\
\cline { 2 - 3 } abnormal
\end{tabular} & $\begin{array}{c}48-\mathrm{hr} \\
\text { PB }^{131} \text { I alone } \\
\text { abnormal }\end{array}$ \\
\hline $\begin{array}{c}\text { Toxic } \\
n=18\end{array}$ & 7 & 6 & 2 & 3 \\
$\begin{array}{c}\text { Non-toxic } \\
n=8\end{array}$ & 1 & 5 & 1 & 1 \\
$\begin{array}{c}\text { PBI not done } \\
n=6\end{array}$ & 1 & 4 & 0 & 1 \\
\hline
\end{tabular}


$\pm 1.94 \mathrm{~cm}^{2}$ for the non-toxic patients. There was no significant difference between the two means.

\section{Comparison of the area of the nodule with the PBI}

The correlation coefficient was 0.0447 , which was not significant.

\section{Response to treatment}

At the time of analysis, fifteen patients had received treatment for their toxic nodule. Ten had received ${ }^{131}$ I therapy, three had had the nodule removed surgically and one had been given carbimazole. There was a good clinical response in fourteen and a partial response in one patient who had received radio-active iodine. Apart from the latter patient whose PBI fell from $9 \cdot 1$ to $8 \cdot 3 \mu \mathrm{g} / 100$ $\mathrm{ml}$, all the other eight patients in whom a PBI was measured had a value which was within normal limits (Fig. 1). All five patients in whom $T_{4}, T_{4} R U R$ and $\mathrm{FT}_{4} \mathrm{I}$ were done had normal values for each of the three indices.

\section{Post-treatment scans}

Six patients rendered euthyroid, on both clinical and in vitro test criteria, had thyroid scans repeated. Four showed uptake over the whole of the thyroid, though in two patients the area of the original nodule still took up relatively more of the ${ }^{131}$ I. In two of the

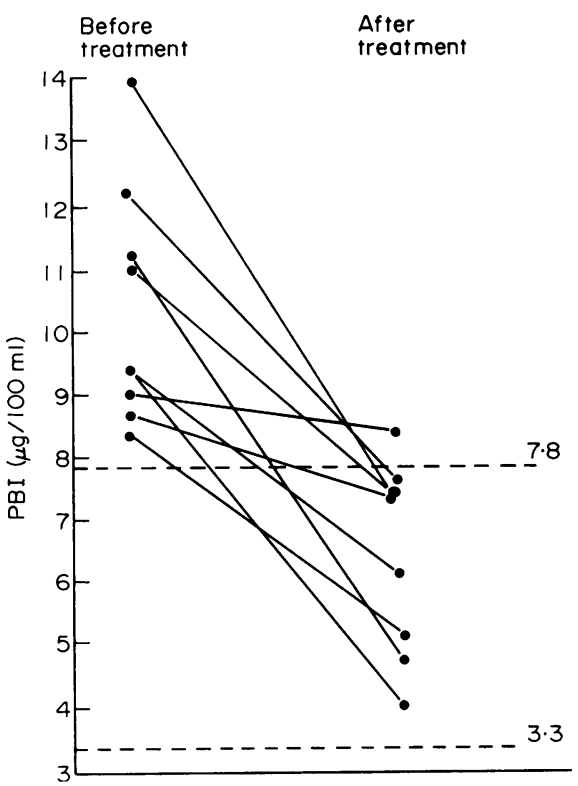

FIG. 1. Showing the reduction in serum protein-bound iodine following treatment in nine patients with solitary toxic nodules. The dotted lines represent the upper and lower limits of normal for the protein-bound iodine. four the uptake was completely uniform. In the remaining two patients the scan still showed a solitary 'hot' nodule.

\section{Discussion}

The division of these patients with solitary 'hot' nodules into two groups, toxic and non-toxic, is necessarily arbitrary as it seems it is possible that there is not an absolute upper limit for the normal PBI (Radcliff et al., 1964; Wayne, Koutras \& Alexander, 1964; Bender, Fitzgerald \& Williams, 1968), although about $90 \%$ of thyrotoxics have levels above the accepted upper limit of normal (Flynn \& Hobbs, 1971). It could also be argued that some of the elevated PBIs in the 'toxic' patients are due to iodinated tyrosines, which have been described in thyrotoxicosis (Farran et al., 1959), or to albumin-migrating iodoproteins, such as have been found in two euthyroid patients with autonomous thyroid nodules (Kahn, Cogan \& Berger, 1962).

Howorth (1970) found a good correlation between $T_{4} I, T_{3}$ RUR, $T_{4}$ RUR and PBI. All five of our patients with a PBI higher than $7.8 \mu \mathrm{g} / 100 \mathrm{ml}$ who had other in vitro tests carried out had results which lay within the toxic range. In contrast, three patients who were thought to be clinically euthyroid and whe had PBIs which were less than $7.8 \mu \mathrm{g} / 100 \mathrm{ml}$ all had in vitro tests confirming a normal thyroid status. good clinical response to treatment in fourteen out of the fifteen patients treated and a partial response in one, documented by a fall in PBI to normal in eight out of nine (Fig. 1), and a normal post-treatment $T_{4}, T_{4} R U R$ and $F_{4} I$ in five patients provides further good evidence that the patients had indeed been originally thyrotoxic. Triiodothyronine $\left(T_{3}\right)$ suppression was not carried out at the time of initial diagnosis, but would not have been of value in deciding whether or not the patient was toxic since several authors have shown that $\mathrm{T}_{3}$ fails to suppress the uptake of ${ }^{131} \mathrm{I}$ by the nodules of many patients who are euthyroid (Perlmutter \& Slater, 1955; Sheline \& McCormack, 1960). Indeed since the effect of the administered $T_{3}$ may be additive to the hormone produced by the hyperfunctioning nodule (Molnar et al., 1965) its use may be harmful to patients, particularly those in cardiac failure.

Although the solitary toxic nodule was previously considered to be a rare cause of thyrotoxicosis, the diagnosis was made in seven instances in this series during the course of 1 year. This is very similar to the average incidence of $8.5 /$ year calculated from the data of Demeester-Mirkine \& Ermans (1967).

The presenting symptoms are often less florid than in Graves' disease but they are of the same type and this is in agreement with the view of Fellinger and his colleagues (Fellinger et al., 1961). The mean age at diagnosis was 58 years, which is very similar to 
the age of 57 found by Demeester-Mirkine \& Ermans (1967) in their series and that of 56 years described by Cope and his co-workers in what was the original paper on the subject of 'hot' nodules (Cope et al., 1947). This mean age is about 10 years older than an unselected group of fifty-four patients with Graves' disease (Ramsay, 1968) though, of course, there is a wide age-range. It would appear from the present data that anxiety and depression occur more commonly as presenting features than is usual in patients with Graves' disease. This may be true, but it is possible that there may be some bias in the data in that a nearby psychiatric hospital (The Maudsley) refers patients with suspected thyrotoxicosis to this hospital.

The clinical picture of 'apathetic hyperthyroidism' described by Wilansky, Kalant \& Wolfson (1959) in patients with single 'hot' nodules was uncommon in our patients, only one being without both symptoms and signs suggestive of thyrotoxicosis. Contrary to a popular belief (Ingbar \& Woeber, 1968) that thyrotoxic myopathy does not occur in patients with toxic nodules, it is of interest to note that one of the patients in this series presented with proximal muscle weakness. As has been noted by others (Fellinger et al., 1961; Molnar et al., 1965), no patient had exophthalmos. It seems clear, therefore, certain specific features apart, that the symptoms and signs produced by the toxic nodule are dependent on the amount of excess thyroid hormone being secreted, and are not qualitatively different from those of Graves' disease. Because of the lack of exophthalmos and of obvious goitre it is necessary to have a high index of suspicion when considering the clinical diagnosis of toxic nodule. Careful examination of the neck will nearly always reveal a palpable nodule as a clue to the diagnosis.

The fact that radio-active iodine uptake is of little value in making a diagnosis of toxic nodule has received little notice in standard endocrine text books and is not mentioned in a recent review of the assessment of thyroid function (Flynn \& Hobbs, 1971). Fellinger and his colleagues did ${ }^{131} \mathrm{I}$ uptakes on sixty patients with hyperfunctioning nodules and found that the 24-hr uptakes ranged from 20 to $70 \%$ and that the uptake did not differentiate between those who were toxic and those who were not (Fellinger et al., 1961). Skillern, McCullagh \& Clamen (1962) in a study of forty-six patients reported normal radio-active iodine uptakes at $24 \mathrm{hr}$ in $54 \%$. Miller and his colleagues (Miller, Horn \& Block, 1964) found that between 40 and $50 \%$ of their toxic patients had ${ }^{131}$ I uptakes within the normal range. A further study (Molnar et al., 1965) showed that only nine out of sixteen patients had an elevated 6-hr uptake and that only nine out of twenty-five $(36 \%)$ had an abnormal uptake at $24 \mathrm{hr}$.
The results in the present study are broadly similar, nine out of eighteen patients having a raised uptake at one or more of the four times measured $(2,6,24$ and $48 \mathrm{hr}$ ). The test was more consistent in the group of non-toxic patients with hyperfunctioning nodules, in that six out of the eight had values within the normal range. It seems therefore that the original statement of Fellinger et al. (1961), that 'routine radio-active iodine tests give no conclusive information about the functional state of the nodule' is correct.

Fellinger et al. (1961) stated that the 48-hr PB $^{131}$ I concentration is elevated in most of the cases, whether the patient be toxic or non-toxic, but they do not quote any figures. In the present series only ten out of eighteen $(55 \%)$ toxic patients had a raised $P^{P{ }^{131} I}$ and the value of this finding is diminished still further by the fact that two out of the eight euthyroid patients also had a raised PB $^{131} I$. This may be due to distribution of the ${ }^{131} \mathrm{I}$ in a diminished thyroidal pool of hormonal iodine (Fellinger et al., 1961). Recent observations (Ramsay \& Clarke, 1972) suggest that the time-scale for the incorporation of labelled iodine into hormone may be different in patients with 'hot' nodules, since many patients with normal $\mathrm{PB}^{131}$ Is at $48 \mathrm{hr}$ have elevated levels at 6 days.

Thyroid scintiscans offer the only sure way of identifying the hyperfunctioning thyroid nodule. They do not indicate whether or not the patient is toxic. It is important to be in full possession of all the clinical facts about the patient before proferring an opinion about the scan. Previous thyroid surgery, the presence of thyroiditis (Miller \& Hamburger, $1965)$ or a multinodular goitre with non-functioning cysts in it and a carcinoma of the thyroid can all lead to the impression that the last remaining area of function is a 'hot' spot with suppression of the rest of the thyroid tissue. A last pitfall is Graves' disease in a patient in whom the mass of one lobe is much greater than that of the other (Miller \& Hamburger, 1965). The scan will show a greater concentration of ${ }^{131} \mathrm{I}$ in this lobe, but this should not be confused with a solitary hyperfunctioning nodule, as the contralateral lobe will show some degree of uptake and not complete suppression. There are, of course, tests which will help to elucidate this problem (Miller \& Hamburger, 1965). Tri-iodothyronine will fail to suppress the uptake in the patient with Graves' disease, but will suppress the extranodular tissue in the patient with a hyperfunctioning nodule in whom there is still some activity in tissue outside the nodule (Demeester-Mirkine \& Ermans, 1967). On the other hand TSH stimulation will have little effect on the scan of the patient with Graves' disease, but will cause the extranodular tissue in the patient with the hyperfunctioning nodule to increase the uptake of ${ }^{131}$ I considerably (Molnar et al., 1965). 
One of the problems associated with thyroid scanning using ${ }^{131} I$ is the relatively high dose of radiation received by the patient compared with other diagnostic radio-isotope techniques (International Commission on Radiation Protection, 1971). If the patient is known to be thyrotoxic before scanning a dose of $20 \mu \mathrm{Ci}^{131} \mathrm{I}$ will produce a scan with good definition. If, on the other hand, the patient presents with a lump in the neck, $50 \mu \mathrm{Ci}$ may have to be used in order to delineate clearly a 'cold' area. It is hoped that the radiation problem may be lessened in the future by the more frequent use of pertechnetate$\mathrm{Tc}^{99 \mathrm{~m}}$ for thyroid scanning (Atkins \& Richards, 1968).

It has been suggested that there is a correlation between the size of the nodule and its function. Skillern and his colleagues (1962) found that none of their toxic patients had a nodule with a diameter on scanning of less than $3 \mathrm{~cm}$. Miller et al. (1964) found that there was no thyrotoxicosis in their patients until the greatest dimension was $3-4 \mathrm{~cm}$. The size of the hyperfunctioning nodules was estimated by planimetry by Demeester-Mirkine \& Ermans (1967). They found that the mean surface-area of the non-toxic nodules was $12.5 \pm 6.1 \mathrm{~cm}^{2}$ (range 5.4 to $30.8 \mathrm{~cm}^{2}$ ), while that for toxic nodules was $26.5 \pm 8.8 \mathrm{~cm}^{2}$ (range $16.0-40.0 \mathrm{~cm}^{2}$ ). No tests of significance were given. In the present series the areas calculated for the toxic nodules were $6.24 \pm 2.76$ $\mathrm{cm}^{2}$ and for the non-toxic nodules $5.20 \pm 1.94 \mathrm{~cm}^{2}$, there being no statistical difference between the two. There was also a poor correlation between the surface area of the nodule and the PBI. In none of the present series was the greatest diameter of the toxic or non-toxic nodule less than $2.5 \mathrm{~cm}$. From the present evidence it would seem that there is no positive evidence of a correlation between the size of the nodule and its functional activity, and it implies that the degree of hyperfunction depends on the activity of its individual cells rather than on the cell mass.

Two suggestions in relation to solitary toxic nodules may be put forward. Firstly we suspect that intermittent secretion of thyroid hormone may occur in patients with toxic nodules. Two patients in this series exhibited a temporary spontaneous improvement in the clinical features of thyrotoxicosis, paralleled by a return of elevated in vitro thyroid function tests to the normal range. Subsequent recurrence of clinical thyrotoxicosis was accompanied by elevated thyroid hormone levels in the blood. Secondly, we have noted that some patients with solitary 'hot' nodules may have elevated ${ }^{131}$ I uptakes, with or without raised 48-hr PB $^{131}$ Is, despite normal thyroxine and resin uptake measurements. This may reflect a reduced intrathyroidal iodine pool, but it is worth considering whether some of the patients with symptoms suggestive of thyrotoxicosis might have triiodothyronine thyrotoxicosis (Maclagan, Bowden \& Wilkinson, 1957; Shimaoka, 1963; Sterling et al., 1969). Studies are currently being carried out into the concentration of triiodothyronine in the serum of patients with solitary hyperfunctioning nodules in order to elucidate this problem.

\section{Acknowledgments}

We are grateful to Dr D. J. Durden-Smith, Miss P. D. Glover and Mr M. B. Clarke for their help and co-operation in this study and to Miss H. E. A. Farran and Dr P. J. N. Howorth for thyroxine and resin uptake measurements.

\section{Addendum}

Since this paper was written, Hollander and his colleagues have reported eight patients with autonomous adenomata in whom conventional tests of thyroid function, including serum $T_{4}$, were normal, but who all had elevated levels of circulating triiodothyronine (Hollander, C.S., Mitsuma, T., Nihei, N., Shenkman, L., Burday, S.Z. and Blum, M. (1972) Clinical and laboratory observations in cases of triiodothyronine toxicosis confirmed by radio-immunoassay. Lancet, i, 609).

\section{References}

Atkins, H.L. \& Richards, P. (1968) Assessment of thyroid function and anatomy with technetium-99m as pertechnetate. Journal of Nuclear Medicine, 9, 7.

Bender, C.E., Fitzgerald, L.T. \& Williams, C.M. (1968) Probability values for protein-bound iodine, thyroid ${ }^{131} \mathrm{~K}$ uptakes and $T_{3}$ resin uptakes for hypothyroidism, euthyroidism and hyperthyroidism. American Journal of Roentgenology, 103, 886.

Cope, O., Rawson, R.W. \& McArthur, J.W. (1947) The hyperfunctioning single adenoma of the thyroid. Surgery, Gynecology and Obstetrics, 84, 415.

Demeester-Mirkine, N. \& Ermans, A.M. (1967) Euthyroid 'hot' nodules: a physiological approach. In: Thyrotoxicosis (Ed. by W. J. Irvine), p. 68. Proceedings of an International Symposium, Edinburgh.

Farran, H.E.A., Lea, A.J., Goolden, A.W.G. \& Abbatt, J.D. (1959) Iodinated tyrosines in the plasma of patients with thyrotoxicosis. Lancet, i, 793.

Fellinger, K., Höfer, R., Egert, H. \& Vetter, H. (1961) Clinical and laboratory observations in patients with hyperactive thyroid nodules. In: Advances in Thyroid Research (Ed. by R. Pitt-Rivers), p. 347. Pergamon Press, Oxford.

FLYNN, F.V. \& HobBS, J.R. (1971) The assessment of thyroid function. Annals of Clinical Biochemistry, 8, 59.

HowORTH, P.J.N. (1970) In vitro thyroid function tests using ${ }^{125}$ I-labelled tri-iodothyronine and thyroxine. Annals of Clinical Biochemistry, 7, 55.

INGBAR, S.H. \& WOEBER, K.A. (1968) In: Textbook of Endocrinology (Ed. by R. H. Williams), p. 228. Saunders, Philadelphia.

International Commission on Radiological Protection (1971) Protection of the Patient in Radionuclide Investigations. Publication 17, Oxford.

KahN, A., Cogan, S.R. \& Berger, S. (1962) Circulating iodoprotein in two patients with autonomous thyroid nodules. Journal of Clinical Endocrinology and Metabolism, 22, 1.

Maclagan, N.F., Bowden, C.H. \& Wilkinson, J.H. (1957) The metabolism of thyroid hormones. 2. Detection of thyroxine and tri-iodothyronine in human plasma. Biochemical Journal, 67, 5. 
Maclagan, N.F. \& HoworTh, P.J.N. (1969) Thyroid function studies using uptake of radio-active thyronines from serum and total thyroxine assay; the free thyroxine index. Clinical Science, 37, 45.

Miller, J.M. \& Hamburger, J.L. (1965) The thyroid scintigram. I. The hot nodule. Radiology, 84, 66.

Miller, J.M., HorN, R.C. \& Block, M.A. (1964) The evolution of toxic nodular goiter. Archives of internal Medicine, 113, 72.

Molnar, G.D., Wilber, R.D., Lee, R.E., Woolner, L.B. \& KeatiNG, F.R. (1965) On the hyperfunctioning solitary thyroid nodule. Mayo Clinic Proceedings, 40, 665.

MurPhy, B.E.P. \& PATteE, C.J. (1964) Determination of thyroxine utilizing the property of protein binding. Journal of Clinical Endocrinology and Metabolism, 24, 187.

Perlmutter, M. \& Slater, S. (1955) Use of thyroid hormone to differentiate between hyperthyroidism and euthyroidism. Journal of the American Medical Association, 158, 718.

Radcliff, F.J., Baker, J.M., Croydon, M.J., Hart, M.J. \& Hales, I.B. (1964) Diagnostic value of the estimation of protein bound iodine in thyroid disease; survey of an Australian population group. Journal of Clinical Endocrinology and Metabolism, 24, 883.

Ramsay, I.D. (1968) Thyrotoxic muscle disease. Postgraduate Medical Journal, 44, 385.

Ramsay, I.D. \& Clarke, M.B. (1972) Unpublished.
Riley, M. \& Gochman, N. (1964) A fully automatic method for the determination of serum protein bound iodine. Technicon International Symposium 1964. Technicon Instrument Corporation, Chauncey, New York.

Roualle, H.L.M. (1949) The solitary thyroid nodule and thyrotoxicosis. British Journal of Surgery, 36, 312.

Sheline, G.E. \& McCormack, K. (1960) Solitary hyperfunctioning thyroid nodules. Journal of Clinical Endocrinology and Metabolism, 20, 1401.

ShimaOKA, K. (1963) Toxic adenoma of the thyroid, with triiodothyronine as the principal circulating thyroid hormone. Acta endocrinologica, 43, 285.

Silverstein, G.E., Burke, G. \& Cogan, R. (1967) The natural history of the autonomous hyperfunctioning thyroid nodule. Annals of Internal Medicine, 67, 539.

Skillern, P.G., McCullagh, E.P. \& Clamen, M. (1962) Radio-iodine in diagnosis and therapy of hyperthyroidism. Hyperthyroidism caused by hyperfunctioning thyroid adenoma. Archives of Internal Medicine, 110, 888.

Sterling, K., Bellabarba, D., Newman, E.S. \& Brenner, M.A. (1969) Determination of tri-iodothyronine concentration in human serum. Journal of Clinical Investigation, 48, 1150 .

Wayne, E.J., Koutras, D.A. \& Alexander, W.D. (1964) In: Clinical Aspects of Iodine Metabolism, p. 176. Blackwe ll Scientific Publications, Oxford.

Wilansky, D.L., Kalant, N. \& Wolfson, J. (1959) Thyroid function in apathetic hyperthyroidism. Canadian Medical Association Journal, 80, 805. 